BMJ Open

Diabetes

Research

\& Care

\section{Need for improved diabetes support among people with psychiatric disorders and diabetes treated in psychiatric outpatient clinics: results from a Danish cross-sectional study}

To cite: Knudsen L, Hansen DL, Joensen LE, et al. Need for improved diabetes support among people with psychiatric disorders and diabetes treated in psychiatric outpatient clinics: results from a Danish crosssectional study. BMJ Open Diab Res Care 2022;10:e002366. doi:10.1136/

bmjdrc-2021-002366

- Additional supplemental material is published online only. To view, please visit the journal online (http://dx.doi. org/10.1136/bmjdrc-2021002366).

Received 4 May 2021 Accepted 4 January 2022

Check for updates

C Author(s) (or their employer(s)) 2022. Re-use permitted under CC BY-NC. No commercial re-use. See rights and permissions. Published by BMJ.

For numbered affiliations see end of article.

Correspondence to Lenette Knudsen; lenette.knudsen@regionh.dk

\section{ABSTRACT}

Introduction People with psychiatric disorders have increased risk of premature death partly due to diabetes. This study aims to explore the quality of diabetes care, diabetes management, diabetes support and well-being of people with psychiatric disorders and diabetes.

Research design and methods A total of 107 participants aged $\geq 18$ years with diabetes and psychiatric disorders treated at psychiatric outpatient clinics in Denmark were recruited from August 2018 to June 2019. This descriptive cross-sectional study includes data from medical records on quality of diabetes care (eg, level and annual examination of hemoglobin $\left.\mathrm{A} 1 \mathrm{c}\left(\mathrm{HbA}_{1 \mathrm{c}}\right)\right)$ and questionnaires on diabetes management (measured on items from the Summary of Diabetes Self-Care Activities Scale and diabetes distress based on Problem Areas in Diabetes Scale (PAID-5)), diabetes support (no, some or high support from eight potential support persons and experience of care actions measured on items from Patient Assessment of Chronic IIIness Care) and well-being (WHO 5-Item Scale and self-rated general health).

Results The mean age was 52 years, $56 \%$ were men, the mean body mass index was $31.9 \mathrm{~kg} / \mathrm{m}^{2}$, the median $\mathrm{HbA}_{1 \mathrm{c}}$ was $53 \mathrm{mmol} / \mathrm{mol}(7.0 \%)$ and the mean blood pressure was $131 / 83 \mathrm{~mm} \mathrm{Hg}$. The proportion with annual measurements of $\mathrm{HbA}_{1 \mathrm{c}}$ was $93 \%$, blood pressure $80 \%$, cholesterol $93 \%$, foot examination $77 \%$ and eye examination $75 \%$. Fifty-one per cent had high diabetes distress (PAID-5 score $\geq 8$ ). Diabetologists and general practitioners (39\% and $37 \%)$ were the health professionals most frequently reported to provide high diabetes support.

Conclusions This study highlights a need for improved diabetes support in people with psychiatric disorders and diabetes. Although a high proportion received appropriate diabetes care, we found high levels of diabetes distress, moderate levels of optimal self-management behaviors, low well-being and low diabetes support from psychiatric health professionals, while one-third of the population found it relevant to receive diabetes support from psychiatric health professionals.

\section{Significance of this study}

What is already known about this subject?

- People with psychiatric disorders and diabetes have higher prevalence of diabetes complications and premature death and experience additional barriers to managing diabetes compared with people with diabetes only.

What are the new findings?

- Diabetes care was within national treatment guidelines in people with diabetes and psychiatric disorders treated at psychiatric outpatient clinics.

- In this population half had high diabetes distress and moderate level of optimal self-management behaviors and majority had low well-being and poor selfrated health.

- More than a third did not experience high diabetes support from any of their healthcare providers, while a third expressed a high relevance of getting diabetes support from psychiatric health professionals.

How might these results change the focus of research or clinical practice?

- Future research should investigate how to integrate diabetes and psychiatric care and identify interventions aiming to address the needs and difficulties identified in the present study.

- Increasing awareness and support from psychiatric health professionals in diabetes-related problems may be needed to enhance diabetes care and management in people with coexisting psychiatric disorders and diabetes.

\section{INTRODUCTION}

People with psychiatric disorders have three to four times higher prevalence of diabetes than the background population, ${ }^{1}$ and the coexistence of psychiatric disorders and diabetes is associated with a higher prevalence of diabetes complications and death. ${ }^{1-3}$ This is 
partly due to the side effects associated with psychotropic drugs (particularly antipsychotics), unhealthy lifestyle and inadequate diabetes management. ${ }^{4}$ The psychiatric disorders often overshadow diabetes care among professionals and patients, and treatment of psychiatric disorders and diabetes in two compartmentalized health systems might contribute to the higher prevalence of complications and death. ${ }^{4}$ Currently, the general practitioner or specialist at the diabetes hospital is responsible for diabetes treatment.

Studies have found lower quality of diabetes care among people with psychiatric disorders and diabetes compared with people with diabetes. ${ }^{5-9}$ In people with diabetes, lower quality of diabetes care is associated with high diabetes distress defined as worries, concerns and fears related to diabetes, ${ }^{10}{ }^{11}$ which is associated with lower quality of life ${ }^{12}$ and challenges in diabetes selfcare. ${ }^{13}$ Diabetes distress is distinct from depression, but depression and diabetes distress are significantly associated. ${ }^{11}$ Increased levels of diabetes distress have been found in people with major depression and diabetes. ${ }^{14}$ One study found increased level of diabetes distress in people with psychiatric disorders and diabetes, however without quantifying the proportion of people with diabetes distress. ${ }^{15}$ Few studies have examined quality of life $\mathrm{e}^{16-18}$ and diabetes self-care ${ }^{14} 1920$ in people with psychiatric disorders and diabetes. High diabetes distress and low quality of life are likely to be even more prevalent in people with psychiatric disorders and diabetes compared with people with diabetes only, and psychiatric disorders may add additional barriers to diabetes selfmanagement. ${ }^{1521}$

Studies have found that people with psychiatric disorders need more diabetes support both from somatic and psychiatric health providers; ${ }^{22}{ }^{23}$ however, the current level of support received by this population has not yet been established. This descriptive cross-sectional study aims to explore the quality of diabetes care, behavioral and emotional diabetes management, level of diabetes support, and quality of life of people with psychiatric disorders and diabetes treated at psychiatric outpatient clinics in Denmark.

\section{MATERIALS AND METHODS}

\section{Design and study population}

This study is a descriptive cross-sectional study conducted as part of a pragmatic, controlled cluster trial on the effectiveness of a diabetes training course targeted to psychiatric nurses (trial registration number ISRCTN15523920). The present study describes data obtained before the diabetes training course.

Persons 18 years or older with psychiatric disorders and any type of diabetes treated at eight psychiatric outpatient clinics in the Capital Region of Denmark were recruited between August 2018 and June 2019. Psychiatric health professionals identified persons with diabetes and invited them to participate in the study when they attended

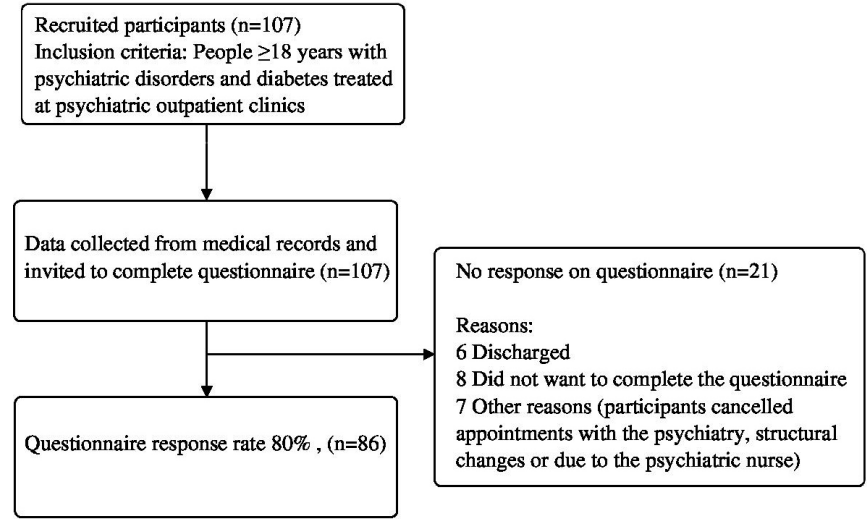

Figure 1 Flow chart of the data collection process.

routine care visits at psychiatric outpatient clinics. Study enrollment and the data collection process are shown in figure 1 .

\section{Data collection}

Diabetes care was measured according to national guidelines ${ }^{24-26}$ based on self-reported annual eye and foot screening from a questionnaire, and levels of the last obtained laboratory measurement of body mass index (BMI), hemoglobin A1c $\left(\mathrm{HbA}_{1 c}\right)$, cholesterol, low-density lipoprotein cholesterol (LDL cholesterol), high-density lipoprotein cholesterol (HDL cholesterol), triglyceride, estimated glomerular filtration rate (eGFR) and blood pressure, and annual assessments of $\mathrm{HbA}_{1 \mathrm{c}}$, cholesterol, eGFR and blood pressure from the medical records.

Annual assessments of laboratory measurements were calculated as any obtained measurement in the past 12 months. Levels of laboratory measurement were based on the latest obtained measurement.

Data obtained from medical records also included medication, diabetes diagnoses including type 1 diabetes, type 2 diabetes, other or unspecified, and psychiatric diagnoses including schizophrenia and other psychotic disorders, affective mental disorders, nervous and stressrelated disorders, psychiatric and behavioral disorders due to psychoactive drugs, disorders in personality and behavioral disorder in adulthood, or other psychiatric disorders.

Diagnosis codes were recoded into diagnoses, and diabetes and psychiatric medications were coded as shown in online supplemental table 1. Psychiatric diagnoses included all diagnoses from the medical records, which allowed more than one diagnosis per individual. The proportion of persons with annual assessments of $\mathrm{HbA}_{1 c}$, blood pressure and lipids in 2018 was computed.

All participants were invited to complete a 31-item questionnaire on participant characteristics (civil and work status, residence, education, any hospitalization, diabetes care provider and year of diabetes diagnosis), self-reported annual eye and foot screening, behavioral and emotional diabetes management, experience of diabetes support and care, and quality of life. The questionnaire was handed out by the psychiatric 
health professional during a routine visit at the psychiatric outpatient clinic. The participants were instructed to complete the questionnaire and hand it in before leaving the clinic.

Data were manually double-entered by a data entry person in an electronic data capture tool REDCap (Research Electronic Data Capture) hosted by the Capital Region of Denmark.

\section{Behavioral and emotional management of diabetes}

Behavioral diabetes management was measured using a revised version of the Summary of Diabetes Self-Care Activities Scale. ${ }^{27}$ Participants reported the number of days during the past 7 days when they had eaten a healthy diet, participated in physical activities for $\geq 30 \mathrm{~min}$, measured blood glucose and adherence to prescribed medication. Emotional diabetes management was measured as the level of diabetes distress using the short form of the Problem Areas in Diabetes Scale (PAID5). ${ }^{28}{ }^{29}$ All five items regarding possible problem areas were rated from $0=$ 'not a problem' to $4=$ ='severe problem' and summated to a total score from 0 to 20 . The total score was dichotomized into scores $\geq 8$, indicating high diabetes distress. ${ }^{29}$ Impact of diabetes on everyday life was measured by a question developed for the present study, asking participants to rate 'how much does diabetes impact your everyday life' on a scale from $1=$ 'no impact' to $10=$ 'high impact'.

\section{Diabetes support and experience of diabetes care actions}

Diabetes-specific social support was measured as the level of diabetes support over the past 12 months. Support from eight potential support persons was rated as 'high', 'some' or 'no' support or 'don't have any'. This was based on a question from the Diabetes Attitudes, Wishes and Needs (DAWN) Support for Diabetes SelfManagement Profile study. ${ }^{30}$ The question was modified for the present study to include potential support persons relevant to the study population, including diabetologist, psychiatric nurse, psychiatrist, psychologist, social educational support person, home support and family, friends and people close to the person with psychiatric disorders and diabetes. Relevance of getting diabetes support from the psychiatric nurse was measured on a scale, developed for the present study, rated from $1=$ 'not relevant' to $10=$ 'highly relevant'. Participants' experience of diabetes care actions provided by the psychiatric nurse over the past 6 months was measured using individual items from two subscales from the Patient Assessment of Chronic Illness Care questionnaire.$^{31}{ }^{32}$ The two subscales measured three actions related to problemsolving and four actions related to coordination and follow-up related to diabetes with the question 'over the past 6 months, when I received care for my psychiatric disease, I was... for example, referred to a dietitian or another healthcare professional, who can support my diabetes'.

\section{Well-being and self-rated general health}

Well-being in the past 2 weeks was measured by the WHO 5-Item Scale (WHO-5) ${ }^{33}$ All five items were rated from $0=$ 'at no time' to $5=$ 'all of the time', summarized and multiplied by 4 into a composite score from 0 to 100 . WHO-5 scores were dichotomized into scores $\geq 28$, indicating likely depression and $<50$ indicating low wellbeing. ${ }^{33}$ Self-rated health was measured with the validated question 'In general, would you say your health is:', with the answer categories 'poor', 'fair', 'good', 'very good' or 'excellent'.

\section{Statistical analysis}

Descriptive statistics were used to summarize information on participant characteristics, indicators of diabetes care, behavioral and emotional management of diabetes, experience of diabetes support and care, and quality of life. Categorical variables were presented as proportions and continuous variables as mean (SD) or median (IQR) for non-normal distributed continuous variables. Diabetes duration was computed by self-reported year of diabetes diagnosis subtracted from the year 2019.

Data were analyzed using the statistical software $\mathrm{R}$ V.3.6.0 (R Foundation for Statistical Computing).

Interested and eligible persons were given written and verbal information about the study before giving oral and written informed consent to participate.

\section{RESULTS}

A total of 107 persons with psychiatric disorders and diabetes treated at psychiatric outpatient clinics were recruited for the study, of whom $80 \%$ (86 of 107) completed the questionnaire, as shown in figure 1 . No differences were found in age, sex, type of diabetes, $\mathrm{HbA}_{1 \mathrm{c}}$ or BMI between those completing the questionnaire and those declining (online supplemental table 2).

The characteristics of the study population are presented in table 1. Differences between psychiatric disorders are presented in online supplemental table 3 .

The mean age was 52 years $(\mathrm{SD}=12), 56 \%$ were men and $95 \%$ reported neither working nor studying. The mean of the last obtained measurement of BMI was $31.9 \mathrm{~kg} / \mathrm{m}^{2}(\mathrm{SD}=6.9)$ and $85 \%$ were classified as overweight $\left(\right.$ BMI $>25 \mathrm{~kg} / \mathrm{m}^{2}$ ), of whom $33 \%$ were classified in obese class I $\left(\mathrm{BMI}=30-<35 \mathrm{~kg} / \mathrm{m}^{2}\right), 17 \%$ in obese class II (BMI $\left.\geq 35-40 \mathrm{~kg} / \mathrm{m}^{2}\right)$ and $8 \%$ in obese class III $\left(\mathrm{BMI} \geq 40 \mathrm{~kg} / \mathrm{m}^{2}\right)$. Thirty-nine per cent reported smoking every day.

The median (IQR) duration of diabetes was 10 years (4-15) $79 \%$ were diagnosed with type 2 diabetes, $11 \%$ diagnosed with type 1 diabetes and $10 \%$ with other or unspecified diabetes.

Diagnoses of any psychiatric disorders included schizophrenia and other psychotic disorders (59\%), affective mental disorders $(22 \%)$, nervous and stress-related disorders (14\%), psychiatric and behavioral disorders due to psychoactive drugs $(12 \%)$, disorders in personality and 
Table 1 Characteristics of people with psychiatric disorders and diabetes from eight psychiatric outpatient clinics in Denmark $(\mathrm{N}=107)$

\begin{tabular}{|c|c|}
\hline & $\begin{array}{l}\text { Mean (SD), median } \\
\text { (IQR) or } n(\%)\end{array}$ \\
\hline Age in years & $51.6(11.8)$ \\
\hline Men & $60(56.1)$ \\
\hline \multicolumn{2}{|l|}{ Diabetes type } \\
\hline Type 1 diabetes & $12(11.2)$ \\
\hline Type 2 diabetes & $84(78.5)$ \\
\hline Other or unspecified diabetes & $11(10.3)$ \\
\hline Diabetes duration in years ${ }^{*}$ & $10.0(4.0-15.0)$ \\
\hline \multicolumn{2}{|c|}{ Level of last obtained clinical measurement of } \\
\hline Body mass index $\left(\mathrm{kg} / \mathrm{m}^{2}\right)$ & $31.9(6.9)$ \\
\hline $\mathrm{HbA}_{1 \mathrm{c}}(\mathrm{mmol} / \mathrm{mol})$ & $53(43-67)$ \\
\hline $\mathrm{HbA}_{1 \mathrm{c}}(\%)$ & $7.0(6.1-8.3)$ \\
\hline LDL cholesterol (mmol/L) & $2.1(0.9)$ \\
\hline HDL cholesterol (mmol/L) & $1.2(0.4)$ \\
\hline Triglyceride (mmol/L) & $2.0(1.3-3.5)$ \\
\hline $\begin{array}{l}\text { Blood pressure, systolic/ } \\
\text { diastolic }(\mathrm{mm} \mathrm{Hg})\end{array}$ & $131 / 83(17 / 12)$ \\
\hline eGFR $\left(\mathrm{mL} / \mathrm{min} / 1.73 \mathrm{~m}^{2}\right)$ & $90(84-90)$ \\
\hline \multicolumn{2}{|c|}{ Diabetes treatment, according to medical journals } \\
\hline Metformin & $75(70.1)$ \\
\hline SGLT2 & $20(18.7)$ \\
\hline DPP4 & $16(15.0)$ \\
\hline GLP-1 & $11(10.3)$ \\
\hline Insulin & $32(29.9)$ \\
\hline \multicolumn{2}{|l|}{ Psychiatric diagnoses $\dagger$} \\
\hline $\begin{array}{l}\text { Schizophrenia and other } \\
\text { psychotic disorders }\end{array}$ & $63(58.9)$ \\
\hline Affective mental disorders & $23(21.5)$ \\
\hline $\begin{array}{l}\text { Nervous and stress-related } \\
\text { disorders }\end{array}$ & $15(14.0)$ \\
\hline $\begin{array}{l}\text { Psychiatric and behavioral } \\
\text { disorders due to psychoactive } \\
\text { drugs }\end{array}$ & $13(12.1)$ \\
\hline $\begin{array}{l}\text { Disorders in personality and } \\
\text { behavioral disorder in adulthood }\end{array}$ & $9(8.4)$ \\
\hline Other psychiatric disorders & $15(14.0)$ \\
\hline \multicolumn{2}{|c|}{ Psychiatric medication, according to medical journals } \\
\hline Antipsychotic treatment & 85 (79.4) \\
\hline Benzodiazepine treatment & 37 (34.6) \\
\hline Antidepressant treatment & $45(42.1)$ \\
\hline Mood stabilizers & $11(10.3)$ \\
\hline \multicolumn{2}{|c|}{ Education: highest qualification, ${ }^{*}$ self-reported } \\
\hline Low & $29(34.9)$ \\
\hline Medium & $28(33.7)$ \\
\hline High & $26(31.3)$ \\
\hline
\end{tabular}

Continued
Table 1 Continued

Mean (SD), median (IQR) or $\mathrm{n}(\%)$

\begin{tabular}{ll}
\hline Relationship status, ${ }^{*}$ self-reported \\
Married/in a relationship & $29(34.1)$ \\
\hline Cohabitation, ${ }^{*}$ self-reported & \\
\hline Institution & $7(8.3)$ \\
\hline Living alone & $53(63.1)$ \\
\hline Living with someone & $24(28.6)$ \\
\hline
\end{tabular}

*Missing data: diabetes duration $n=36$, education $n=24$, relationship status $n=22$ and cohabitation $n=23$.

†Psychiatric diagnoses and diabetes treatment include any diagnosis and any diabetes treatment from the medical records, allowing each participant to have more than one. DPP4, dipeptidyl peptidase-4; eGFR, estimated glomerular filtration rate; GLP-1, glucagon-like peptide-1; $\mathrm{HbA}_{1}$, hemoglobin A1c; HDL cholesterol, high-density lipoprotein cholesterol; LDL cholesterol, low-density lipoprotein cholesterol; SGLT2, sodiumglucose cotransporter-2.

behavioral disorder in adulthood $(8 \%)$, and other psychiatric disorders (14\%).

\section{Indicators of diabetes care}

Diabetes care outcomes are presented in table 2. Differences in quality of diabetes care outcomes between the psychiatric disorders are presented in online supplemental table 4 .

In the past year 93\%, $80 \%$ and $93 \%$ had a measurement of $\mathrm{HbA}_{1 \mathrm{c}}$, blood pressure and cholesterol, respectively, according to the medical records, while $77 \%$ and $75 \%$ reported to have received a foot or eye examination in the past year.

\section{Behavioral and emotional management of diabetes}

In table 2 the results on behavioral and emotional management of diabetes, diabetes support and wellbeing are presented. The most frequent weekly selfmanagement activity reported among the participants was taking prescribed medication (median 7 days), followed by healthy eating (median 4 days), whereas the least frequent was blood glucose measurement (median 1 day) and being physically active (median 2.5 days). High diabetes distress (PAID- 5 score $\geq 8$ ) was prevalent in $51 \%$ of the population. Diabetes' impact on everyday life varied greatly in the study population, $29 \%$ reported the highest scores from 8 to 10, indicating high impact, and $29 \%$ reported the lowest scores from 1 to 3 , indicating lower impact.

\section{Experience of well-being and diabetes support}

Approximately $64 \%$ reported 'poor' or 'fair' self-rated health, while $8 \%$ indicated 'excellent' or 'very good' selfrated health. Furthermore, 33\% had likely depression (WHO-5 $\leq 28$ ) and $70 \%$ had low well-being according to the WHO-5 score (WHO-5 <50) (table 2). 
Table 2 Quality of diabetes care, behavioral and emotional management of diabetes, and quality of life of people with diabetes from psychiatric outpatient clinics in Denmark $(\mathrm{N}=107)$

Mean (SD), median (IQR) or $\mathbf{n}(\%)$

\begin{tabular}{|c|c|}
\hline \multicolumn{2}{|l|}{ Participants with a measurement in the past year for } \\
\hline $\mathrm{HbA}_{1 \mathrm{c}}$ & $99(92.5)$ \\
\hline Blood pressure & $86(80.4)$ \\
\hline Cholesterol & $99(92.5)$ \\
\hline Foot examination* & $65(76.5)$ \\
\hline Eye examination* & $64(75.3)$ \\
\hline \multicolumn{2}{|l|}{ Self-management behaviors in the last 7 days $\dagger$} \\
\hline Days following a healthful eating plan* (range $0-7$ ) & $4.0(2.0-6.0)$ \\
\hline $\begin{array}{l}\text { Days participating in } \geq 30 \text { min physical activity* } \\
\text { (range } 0-7 \text { ) }\end{array}$ & $2.5(0.0-5.0)$ \\
\hline $\begin{array}{l}\text { Days taken prescribed diabetes medication* } \\
\text { (range } 0-7 \text { ) }\end{array}$ & $7.0(7.0-7.0)$ \\
\hline $\begin{array}{l}\text { Days testing blood sugar* (sensor=7 days) (range } \\
0-7 \text { ) }\end{array}$ & $1.0(0.0-6.0)$ \\
\hline \multicolumn{2}{|l|}{ Diabetes distress ${ }^{*} \ddagger$} \\
\hline Composite score (range 0-20) & $8(5)$ \\
\hline Proportion with high diabetes distress (score $\geq 8$ ) & $43(50.6)$ \\
\hline \multicolumn{2}{|l|}{ General well-being*§ } \\
\hline Composite score & $42(23)$ \\
\hline Proportion with likely depression (score $\leq 28$ ) & $27(32.5)$ \\
\hline Proportion with low well-being (score $<50$ ) & $58(69.9)$ \\
\hline \multicolumn{2}{|l|}{ Self-rated general health*ף } \\
\hline Excellent or very good & $7(8.4)$ \\
\hline Good & $23(27.7)$ \\
\hline Fair & $33(39.8)$ \\
\hline Poor & $20(24.1)$ \\
\hline
\end{tabular}

*Missing data: foot examination $n=22$, eye examination $n=22$, healthful eating plan $n=24$, physical activity $n=23$, taken prescribed medication $n=23$, measuring blood sugar $n=23$, diabetes distress $n=22$, general well-being $n=24$ and self-rated general health $n=24$.

†Based on items from the Summary of Diabetes Self-Care Activities Scale.

$\ddagger$ Based on Problem Areas in Diabetes Scale 5.

§Well-being Index 5-Item Scale (WHO-5).

qlitem 1 from the Medical Outcomes Study (MOS) 36-Item Short-Form Health Survey.

$\mathrm{HbA}_{1 \mathrm{c}}$, hemoglobin A1c.

Figure 2A presents an overview of how much diabetes support the participants experienced to get from each healthcare provider, including diabetes treatment providers and psychiatric health professionals. Overall, $35 \%$ reported no or some support from all healthcare providers, while $36 \%$ reported to get high support from one and 29\% reported high support from at least two healthcare providers.

The most common diabetes treatment provider was the general practitioner $(57 \%)$, followed by diabetologist $(38 \%)$, while $5 \%$ reported not to have any diabetes treatment provider. A total of $33 \%$ reported no diabetes support from the general practitioner and $5 \%$ reported no diabetes support from the diabetologist. The experience of level of diabetes support from the psychiatric nurse was diverse, $19 \%$ reported high, $51 \%$ some and $25 \%$ reported no support.

Similarly, participants' experience of relevance of getting diabetes support from the psychiatric nurse was disparate. Thirty participants $(38 \%)$ reported the lowest scores (1-3) indicating low relevance of getting diabetes support from the psychiatric nurse, while 25 participants $(32 \%)$ reported the highest scores $(8-10), 1=$ not relevant and $10=$ highly relevant (data not shown). Specific diabetes care actions related to problem-solving and coordination/follow-up from the psychiatric nurse were mostly reported between 'none of the time' and 'some of the time' (figure 2B).

The items 'help to make a diabetes treatment plan', 'referred to a health care professional, who can support my diabetes' and 'contacted after a visit to follow-up ' were the items most frequently reported as 'none of the time', respectively $47 \%, 39 \%$ and $37 \%$, while $15 \%, 16 \%$ and $7 \%$ reported 'not relevant' to getting specific diabetes care from the psychiatric nurse on these items. The items 'asked how visits with other health care professionals were going' and 'encouraged to attend community programs' were the items with the highest proportion responding 'always', respectively $19 \%$ and $13 \%$.

\section{DISCUSSION}

This descriptive cross-sectional study describes a study population with diabetes and psychiatric diseases and is to our knowledge the first study to quantify the proportion of diabetes distress among people with coexisting diabetes and various diagnoses of psychiatric disorders. Overall, we found $80 \%-93 \%$ of the population received annual assessments of clinical markers, around $75 \%$ had annual eye and foot examinations, and the mean levels of clinical markers were within the national treatment target. ${ }^{24}$ We found moderate levels of performing diabetes self-management, while half of the study population experienced high diabetes distress and majority experienced low well-being and low self-rated general health.

Most of the participants received high diabetes support from at least one of their treatment providers, while more than a third reported not getting high diabetes support from any of their treatment providers. A third reported getting no diabetes support from their general practitioner.

\section{Indicators of diabetes care}

This is the first study in Denmark to examine the indicators of quality of care in people with different psychiatric disorders treated in psychiatric outpatient clinics. A previous Danish nationwide study was based on a single mental illness, schizophrenia, ${ }^{5}$ and thus direct comparisons are not possible. Nevertheless, when comparing 


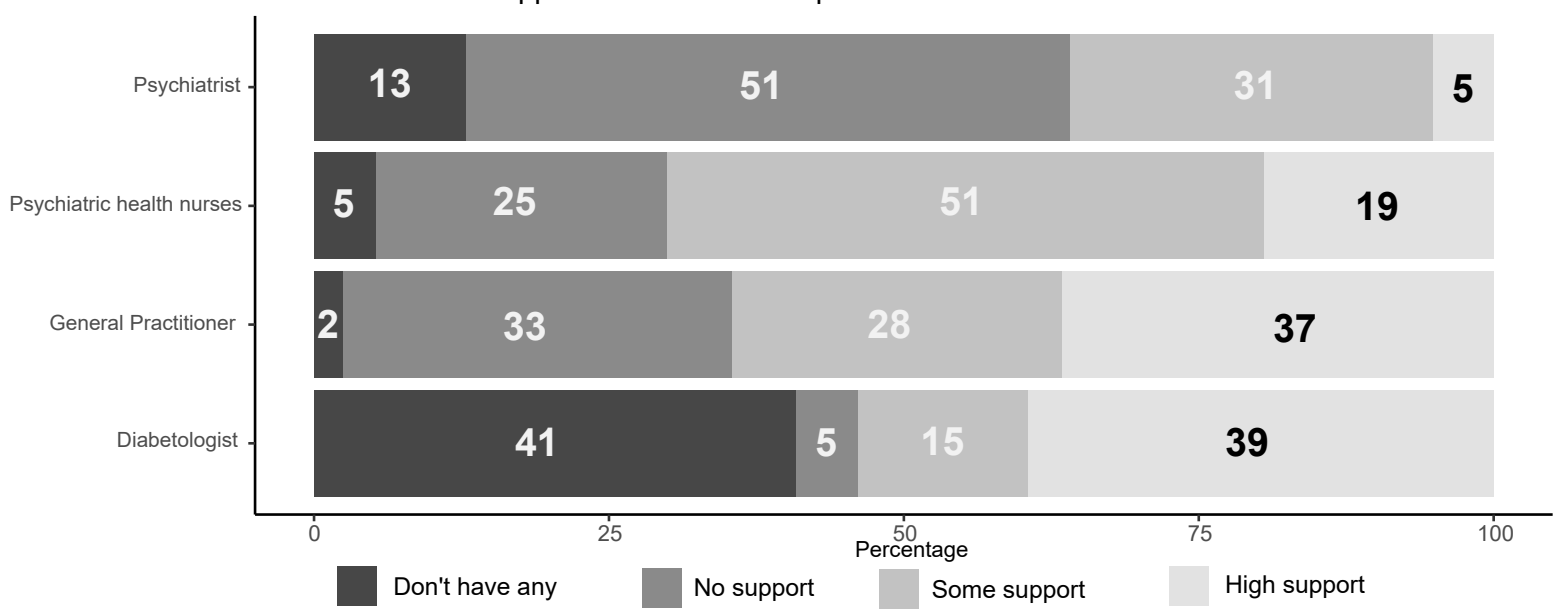

B

Help from the psychiatric health nurses to manage diabetes ${ }^{2}$

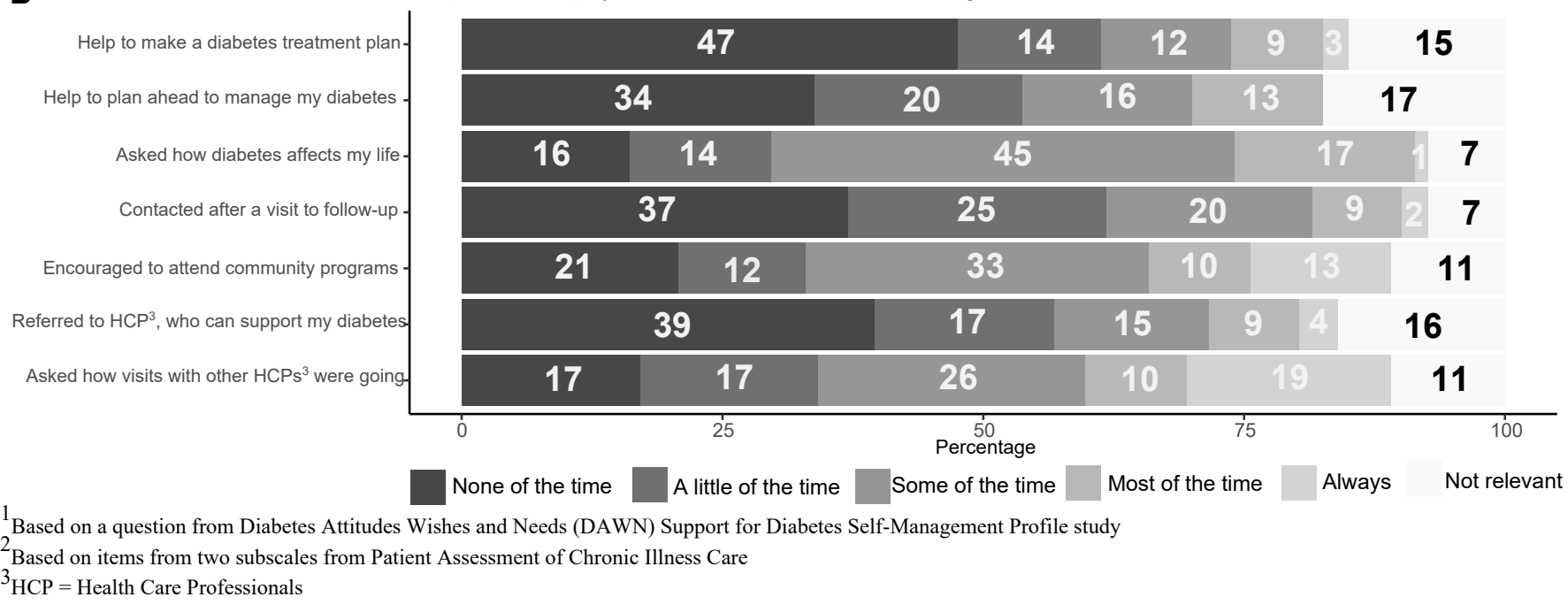

Figure 2 Level of diabetes support from healthcare professionals $(A)$ and help from psychiatric nurses to manage diabetes in the past 6 months $(B)$.

our results with the previous Danish nationwide study, we found a similar proportion with annual monitoring of $\mathrm{HbA}_{1 c}$ and lipids, while a lower proportion had an annual monitoring of blood pressure ( $80 \%$ vs $93 \%$ ), foot examination (77\% vs $87 \%)$ and eye examination $(75 \%$ vs $92 \%$ ). This may be due to differences in validity of the data, where our results on eye and foot examination are based on self-reported data, which may be influenced by recall bias, whereas the previous study is based on data from the Danish Adult Diabetes Registry collected as part of clinical practice. ${ }^{36}$ However, blood pressure was not self-reported and could not be explained by differences in validity of data. When comparing our results with a similar population from mental health clinics in Australia, we found a markedly higher proportion with annual diabetes monitoring in our study. ${ }^{6}$ However, more studies are needed to confirm whether these differences are consistent and to draw conclusions on whether the differences are due to a divergence in access to care or organization of care.
The proportion of annual monitoring was similar for foot examination, but lower for blood pressure and eye monitoring, when comparing our findings with data from the Danish National Diabetes database on people with diabetes. ${ }^{26}{ }^{37}$ The lower rates of blood pressure and eye monitoring may be due to difficulties in managing both psychiatric disorders and diabetes both for the health professionals and the patients, which has been found previously. ${ }^{38}$ Previous studies have also found lower quality of diabetes care in persons with psychiatric disorders and diabetes compared with persons with only diabetes. ${ }^{6} 39$

However, these indicators of quality of diabetes care must be interpreted with caution as several aspects influence the quality of care, including the healthcare providers' action on changes in clinical markers or medication adherence, or other factors influencing diabetes care.

\section{Diabetes management and well-being}

There was a higher medication adherence in our study compared with previous studies among people with 
psychiatric disorders and type 2 diabetes from the $\mathrm{UK}^{19}$ and people with type 2 diabetes from 17 countries from the DAWN study. ${ }^{30}$ Medication adherence was selfreported in our study and in the previous studies. The higher proportion of medication adherence may be due to the fact that medication is free or highly subsidized in Denmark, or due to high support from healthcare professionals or differences in treatments across countries.

Blood glucose testing was less frequent in our study compared with studies among people with psychiatric disorders and type 2 diabetes in the UK and USA ${ }^{19} 40$ and among people with type 2 diabetes in the Danish subpopulation and the entire DAWN study population. ${ }^{30} 34$ However, this may be explained by differences in guidelines for blood glucose testing between the countries or differences in medication treatment, although the lower frequency of blood glucose testing between our study and the Danish DAWN subpopulation may also be related to differences in self-management behaviors in persons with and without psychiatric disorders. The frequency of healthy eating and physical activity is similar to previous studies among people with psychiatric disorders and type 2 diabetes, ${ }^{19} 40$ but lower than studies among people with type 2 diabetes in Denmark ${ }^{41}$ and the DAWN study population. ${ }^{30}$ The lower frequencies of healthy eating and physical activity among persons with psychiatric disorders and diabetes compared with persons with diabetes only are consistent with previous findings from a review which also found that people with diabetes and psychiatric disorders experience additional barriers to diabetes management related to the psychiatric disorder. ${ }^{15}$

Our study found that most of the study population had a low overall quality of life and half of the population experienced high diabetes distress, which previously has been found to be associated with lower quality of diabetes care and diabetes self-care. ${ }^{101342}$ Our results suggest that the coexistence of psychiatric disorders and diabetes is an additional stress factor, and this population experiences more emotional challenges in managing diabetes when living with psychiatric disorders.

Previous research has shown increased levels of diabetes distress in people with major depression in a cross-sectional study in 14 countries $^{43}$ and in people with psychiatric disorders and diabetes. ${ }^{44}$ However, the latter study did not quantify the proportion with high diabetes distress. We found a markedly higher proportion with diabetes distress in our study (51\%) compared with the international study among people with major depression, reporting $12.8 \%$ with moderate to severe diabetes distress measured on a similar PAID score (PAID score $>40) .{ }^{43}$ Similarly, we found the proportion of diabetes distress to be twice as high in our population of people with psychiatric disorders and diabetes $(51 \%$ with diabetes distress) compared with studies among people with diabetes in Denmark (23\% and 26\% with diabetes distress). ${ }^{3445}$ Overall well-being was also substantially lower in this study compared with people with type 2 diabetes from the Danish DAWN subpopulation ${ }^{34}$ and a study among people with diabetes and comorbid mental disorders in Germany. ${ }^{46}$

\section{Diabetes support}

Studies from the UK found results similar to ours, reporting most participants received diabetes support from general practitioners or diabetes specialists, who are also primary diabetes treatment providers. ${ }^{19}{ }^{22}$ Previous studies found that people with psychiatric disorders and diabetes have a higher rate of no-show in the somatic healthcare system and symptoms and attention to psychiatric disorders overshadow management of the somatic disease. ${ }^{41947}$ Persons with psychiatric disorders and diabetes have separate treatment providers for psychiatric and somatic diseases, with limited or no communication between the treatment providers, which creates additional challenges for diabetes care. ${ }^{1947} 48$

Our results indicate appropriate diabetes treatment according to the national treatment guidelines; however, we also found a high proportion with diabetes distress and lower levels of physical activity and healthy diet, which possibly could be improved by more support in the close and frequent contact with psychiatric health professionals. A systematic review found that support from healthcare professionals had a high impact on optimal diabetes management. ${ }^{15}$ Our results show that a third of our study population considered diabetes support from psychiatric nurses highly relevant. This is supported by results from a previous study among people with coexisting psychiatric disorders and diabetes in the UK, which highlighted psychiatric health professionals as an important source of diabetes support and with a potential important role in improving diabetes self-management. ${ }^{22}$

However, the high prevalence of diabetes distress may be due to challenges with emotional regulation, which could be more present in a population with psychiatric disorders. Emotional regulation has previously been associated with diabetes distress in people with type 1 diabetes. ${ }^{49}$ If diabetes distress is high due to challenges with emotional regulation, it is unlikely to decrease without addressing these challenges.

\section{Strengths and limitations}

A strength of the study was the combined clinical and psychosocial data obtained from this hard-to-reach population. Psychosocial health was measured primarily using validated scales and questions, which were tested and adjusted to the study population in a subsample prior to the study.

There was a high response rate to the questionnaires $(80 \%)$, which was possibly due to the study procedures. One of which was that the psychiatric health professionals handled all recruitment and questionnaires as part of usual clinical practice. A limitation of our study may be that we investigated diabetes outcomes from a heterogenic population. This does not allow for interpretation of whether these outcomes would differ depending on the type of diagnosis. 
We experienced significant difficulties in recruiting participants; thus, a limitation of the study was the small study sample. The recruitment strategy entailed recruitment through psychiatric health professionals with pre-established relation to potential study participants. This procedure may have induced selection bias as only people who the psychiatric health professionals knew had diabetes were invited. It is possible that the participants included were the most well functioning who could overcome participation in a study. This may have induced another selection bias and our results may not be representative of all persons with diabetes treated at psychiatric outpatient clinics. Our sample of persons treated at psychiatric outpatient clinics may not reflect the broader group of persons with psychiatric disorders, as persons engaging in psychiatric outpatient clinics may reflect persons who are also more likely to engage in diabetes care.

Some participants did not complete the questionnaire, which may have caused another selection bias, with possible differences in responders and nonresponders. However, we found no differences between those completing the questionnaire and those declining in terms of age, sex, mean of $\mathrm{HbA}_{1 \mathrm{c}}$ or type of diabetes (presented in the online supplemental table). Mean $\mathrm{HbA}_{1 \mathrm{c}}$ and diabetes types are important factors related to the diabetes outcomes examined. However, there may be differences in other outcomes we could not test for.

\section{CONCLUSIONS}

We found a high proportion with diabetes distress, signifying a need for future studies investigating this further. Concurrently, a high proportion received appropriate diabetes care according to the national treatment guidelines and high diabetes support most frequently from somatic health professionals, who currently are the main responsible for providing diabetes support in the Danish healthcare system.

We found a high proportion who did not experience high diabetes support from any of their healthcare providers. A high proportion expressed it was highly relevant to receive diabetes support from psychiatric professionals, while most experienced no or some diabetes support from psychiatric health professionals.

This study highlights a need for increasing diabetes support possibly from psychiatric health professionals to ensure treatment of persons not seen by somatic health professionals and to promote integrated support for all persons with diabetes and psychiatric disorders. This may decrease the level of diabetes distress and increase wellbeing and experience of general health.

\footnotetext{
Author affiliations

${ }^{1}$ Education, Steno Diabetes Center Copenhagen, Gentofte, Denmark

${ }^{2}$ Diabetes Clinic, Steno Diabetes Center Copenhagen, Gentofte, Denmark

${ }^{3}$ Diabetes Management Research, Steno Diabetes Center Copenhagen, Gentofte, Denmark

${ }^{4}$ Clinical Epidemiology, Steno Diabetes Center Copenhagen, Gentofte, Denmark
}

${ }^{5}$ Biological and Precision Psychiatry, Copenhagen Research Centre for Mental Health, Mental Health Centre Copenhagen, Copenhagen University Hospital, Copenhagen, Denmark

${ }^{6}$ Department of Immunology and Microbiology, Faculty of Health and Medical Sciences, University of Copenhagen, Copenhagen, Denmark

${ }^{7}$ Center for Health Research in Greenland, University of Southern Denmark Faculty of Health Sciences, Odense, Denmark

Acknowledgements This study would not have been possible without the great contribution of all psychiatric health professionals from the included psychiatric outpatient clinics in Copenhagen, Denmark, who made great effort in the recruitment and handing out questionnaires.

Contributors LK, DLH, LEJ, MEJ and GSA led the conception, design and planning of the study. LK led the analyses and drafting of the work. All authors contributed to the interpretation of the data and revising it critically for important intellectual content and read and approved the final manuscript. LK is responsible for the overall content as guarantor. LK, DLH and GSA had access to the data and controlled the decision to publish.

Funding This study is funded by Jascha Fonden (case number 6994) and Novo Nordisk Fonden (unrestricted grant to Steno Diabetes Center Copenhagen).

Competing interests LK owns shares in Novo Nordisk A/S. RW owns shares in Novo Nordisk A/S. MEJ has received research grants from Amgen, AstraZeneca, Boehringer Ingelheim, Novo Nordisk and Sanofi-Aventis. MEJ holds shares in Novo Nordisk. GSA owns shares in Novo Nordisk A/S.

Patient consent for publication Not required.

Ethics approval This study involves human participants and was conducted according to the guidelines laid down in the Declaration of Helsinki. The study was approved by the Danish Data Protection Agency (P-2019-338). The Danish Committee on Health Research Ethics assessed that it was not necessary to register the project according to the Danish Act on Research Ethics Review of Health Research Projects ( $\mathrm{H}$-18009189). Participants gave informed consent to participate in the study before taking part.

Provenance and peer review Not commissioned; externally peer reviewed.

Data availability statement Data may be obtained from a third party and are not publicly available.

Supplemental material This content has been supplied by the author(s). It has not been vetted by BMJ Publishing Group Limited (BMJ) and may not have been peer-reviewed. Any opinions or recommendations discussed are solely those of the author(s) and are not endorsed by BMJ. BMJ disclaims all liability and responsibility arising from any reliance placed on the content. Where the content includes any translated material, BMJ does not warrant the accuracy and reliability of the translations (including but not limited to local regulations, clinical guidelines, terminology, drug names and drug dosages), and is not responsible for any error and/or omissions arising from translation and adaptation or otherwise.

Open access This is an open access article distributed in accordance with the Creative Commons Attribution Non Commercial (CC BY-NC 4.0) license, which permits others to distribute, remix, adapt, build upon this work non-commercially, and license their derivative works on different terms, provided the original work is properly cited, appropriate credit is given, any changes made indicated, and the use is non-commercial. See: http://creativecommons.org/licenses/by-nc/4.0/.

\section{ORCID iDs}

Lenette Knudsen http://orcid.org/0000-0001-8969-4640

Dorte Lindqvist Hansen http://orcid.org/0000-0002-4735-6384

Lene Eide Joensen http://orcid.org/0000-0002-4790-8759

Rasmus Wibaek http://orcid.org/0000-0002-4989-2084

Michael Eriksen Benros http://orcid.org/0000-0003-4939-9465

Marit Eika Jørgensen http://orcid.org/0000-0001-8356-5565

Gregers Stig Andersen http://orcid.org/0000-0001-6125-300X

\section{REFERENCES}

1 Wahlbeck K, Westman J, Nordentoft M, et al. Outcomes of Nordic mental health systems: life expectancy of patients with mental disorders. Br J Psychiatry 2011;199:453-8.

2 Ribe AR, Laursen TM, Sandbaek A, et al. Long-term mortality of persons with severe mental illness and diabetes: a population-based cohort study in Denmark. Psychol Med 2014;44:3097-107. 
3 Toender A, Vestergaard M, Munk-Olsen T, et al. Risk of diabetic complications and subsequent mortality among individuals with schizophrenia and diabetes - a population-based register study. Schizophr Res 2020;218:99-106.

4 De Hert M, Cohen D, Bobes J, et al. Physical illness in patients with severe mental disorders. II. barriers to care, monitoring and treatment guidelines, plus recommendations at the system and individual level. World Psychiatry 2011;10:138-51.

5 Jørgensen M, Mainz J, Carinci F, et al. Quality and predictors of diabetes care among patients with schizophrenia: a Danish nationwide study. Psychiatr Serv 2018;69:179-85.

6 Mai Q, Holman C D'Arcy J, Sanfilippo FM, et al. Mental illness related disparities in diabetes prevalence, quality of care and outcomes: a population-based longitudinal study. BMC Med 2011;9:118.

7 Druss BG, Zhao L, Cummings JR, et al. Mental comorbidity and quality of diabetes care under Medicaid: a 50-state analysis. Med Care 2012;50:428-33.

8 Mitchell AJ, Malone D, Doebbeling CC. Quality of medical care for people with and without comorbid mental illness and substance misuse: systematic review of comparative studies. Br J Psychiatry 2009;194:491-9.

9 Smith R, Han L, Ali S, et al. Glucose, cholesterol and blood pressure in type II diabetes: a longitudinal observational study comparing patients with and without severe mental illness. J Psychiatr Ment Health Nurs 2019;26:347-57.

10 Bo $\mathrm{A}$, Jensen $\mathrm{NH}$, Bro F, et al. Higher patient assessed quality of chronic care is associated with lower diabetes distress among adults with early-onset type 2 diabetes: cross-sectional survey results from the Danish DD2-study. Prim Care Diabetes 2020;14:522-8.

11 Snoek FJ, Bremmer MA, Hermanns N. Constructs of depression and distress in diabetes: time for an appraisal. Lancet Diabetes Endocrinol 2015;3:2213-8595 (Electronic)):450-60.

12 Fisher L, Mullan JT, Arean P, et al. Diabetes distress but not clinical depression or depressive symptoms is associated with glycemic control in both cross-sectional and longitudinal analyses. Diabetes Care 2010;33:23-8.

13 Sturt J, Dennick K, Due-Christensen M, et al. The detection and management of diabetes distress in people with type 1 diabetes. Curr Diab Rep 2015;15:101.

14 Mut-Vitcu G, Timar B, Timar R, et al. Depression influences the quality of diabetes-related self-management activities in elderly patients with type 2 diabetes: a cross-sectional study. Clin Interv Aging 2016;11:471-9.

15 Rønne ST, Zabell V, Joensen LE, et al. Perceptions and experiences of living with coexisting type 2 diabetes and severe mental illness: a scoping review. Diabet. Med. 2020;9:1464-5491 (Electronic).

16 Aftab A, Bhat C, Gunzler D, et al. Associations among comorbid anxiety, psychiatric symptomatology, and diabetic control in a population with serious mental illness and diabetes: findings from an interventional randomized controlled trial. Int J Psychiatry Med 2018;53:1541-3527 (Electronic):126-40.

17 Sajatovic M, Gunzler DD, Kanuch SW, et al. A 60-Week prospective RCT of a self-management intervention for individuals with serious mental illness and diabetes mellitus. Psychiatr Serv 2017;68:883-90.

18 Nicolau J, Rivera R, Francés C, et al. Treatment of depression in type 2 diabetic patients: effects on depressive symptoms, quality of life and metabolic control. Diabetes Res Clin Pract 2013;101:1872-8227 (Electronic)

19 Mulligan K, McBain H, Lamontagne-Godwin F, et al. Barriers to effective diabetes management - a survey of people with severe mental illness. BMC Psychiatry 2018;18:165.

20 Ogawa M, Miyamoto Y, Kawakami N. Factors associated with glycemic control and diabetes self-care among outpatients with schizophrenia and type 2 diabetes. Arch Psychiatr Nurs 2011;25:63-73.

21 Gonzalez JS, Delahanty LM, Safren SA, et al. Differentiating symptoms of depression from diabetes-specific distress: relationships with self-care in type 2 diabetes. Diabetologia 2008;51:1822-5.

22 Mulligan K, McBain H, Lamontagne-Godwin F, et al. Barriers and enablers of type 2 diabetes self-management in people with severe mental illness. Health Expect 2017;20:(1369-7625 (Electronic)):1020-30.

23 Knyahnytska Y, Williams C, Dale C, et al. Changing the conversation: diabetes management in adults with severe mental illnesses and type 2 diabetes. Can J Diabetes 2018;42:595-602.

24 Danish Endocrine Society (DES). Treatment guidelines for Type 1 diabetes 2019 [Treatment guidelines for Type 1 diabetes]. Available: https://endocrinology.dk/nbv/diabetes-melitus/type-1-diabetesmellitus/
25 Danish Endocrine Society (DES). Treatment guidelines for type 2 diabetes, 2019. Available: https://endocrinology.dk/nbv/diabetesmelitus/behandling-og-kontrol-af-type-2-diabetes/

26 The Danish Clinical Quality Program (RKKP). Danish diabetes database national annual report 2019/2020, 2020.

27 Toobert DJ, Hampson SE, Glasgow RE. The summary of diabetes self-care activities measure: results from 7 studies and a revised scale. Diabetes Care 2000;23:943-50.

28 Polonsky WH, Fisher L, Earles J, et al. Assessing psychosocial distress in diabetes: development of the diabetes distress scale. Diabetes Care 2005;28:626-31.

29 McGuire BE, Morrison TG, Hermanns N, et al. Short-form measures of diabetes-related emotional distress: the Problem Areas in Diabetes Scale (PAID)-5 and PAID-1. Diabetologia 2010;53:66-9.

30 Nicolucci A, Kovacs Burns K, Holt RIG, et al. Diabetes attitudes, wishes and needs second study (DAWN2 ${ }^{\mathrm{TM}}$ ): cross-national benchmarking of diabetes-related psychosocial outcomes for people with diabetes. Diabet Med 2013;30:767-77.

31 Glasgow RE, Whitesides $\mathrm{H}$, Nelson CC, et al. Use of the patient assessment of chronic illness care (PACIC) with diabetic patients: relationship to patient characteristics, receipt of care, and selfmanagement. Diabetes Care 2005;28:2655-61.

32 Maindal HT, Sokolowski I, Vedsted P. Adaptation, data quality and confirmatory factor analysis of the Danish version of the PACIC questionnaire. Eur J Public Health 2012;22:31-6.

33 Hajos TRS, Pouwer F, Skovlund SE, et al. Psychometric and screening properties of the WHO-5 well-being index in adult outpatients with Type 1 or Type 2 diabetes mellitus. Diabet Med 2013;30:e63-9.

34 Hansen UM, Jones A, Zander M, et al. Denmark's comparative position regarding health status, healthcare provision, selfmanagement and social support: diabetes attitudes, wishes and needs second study (DAWN2). Scand J Public Health 2015;43:111-6.

35 Ware JE, Sherbourne CD. The MOS 36-item short-form health survey (SF-36). I. conceptual framework and item selection. Med Care 1992;30:473-83.

36 Lin EHB, Katon W, Von Korff M, et al. Relationship of depression and diabetes self-care, medication adherence, and preventive care. Diabetes Care 2004;27:2154-60.

37 Holm AL, Andersen GS, Jørgensen ME, et al. Is the rule of halves framework relevant for diabetes care in Copenhagen today? A register-based cross-sectional study. BMJ Open 2018;8:e023211.

38 Stenov V, Joensen LE, Knudsen L, et al. "Mental Health Professionals Have Never Mentioned My Diabetes, They Don't Get Into That": A Qualitative Study of Support Needs in Adults With Type 1 and Type 2 Diabetes and Severe Mental Illness. Can J Diabetes 2020;44:494-500.

39 Kurdyak P, Vigod S, Duchen R, et al. Diabetes quality of care and outcomes: comparison of individuals with and without schizophrenia. Gen Hosp Psychiatry 2017;46:7-13.

40 Gonzalez JS, Safren SA, Cagliero E, et al. Depression, self-care, and medication adherence in type 2 diabetes: relationships across the full range of symptom severity. Diabetes Care 2007;30:2222-7.

41 Juul L, Rowlands G, Maindal HT. Relationships between health literacy, motivation and diet and physical activity in people with type 2 diabetes participating in peer-led support groups. Prim Care Diabetes 2018;12:331-7.

42 Hessler DM, Fisher L, Polonsky WH, et al. Diabetes distress is linked with worsening diabetes management over time in adults with type 1 diabetes. Diabet Med 2017;34:1228-34.

43 Lloyd CE, Nouwen A, Sartorius N, et al. Prevalence and correlates of depressive disorders in people with type 2 diabetes: results from the International prevalence and treatment of diabetes and depression (INTERPRET-DD) study, a collaborative study carried out in 14 countries. Diabet Med 2018;35:(1464-5491 (Electronic)):760-9.

44 Taylor J, Lister J, Boehnke J. The psychosocial impact of having diabetes alongside severe mental illness: Comparing results from the Diabetes Attitudes, Wishes and Needs-Severe Mental Illness (DAWN-SMI) and Diabetes Attitudes, Wishes and Needs Second (DAWN2) studies [abstract]. In: Proceedings of the diabetes UK professional conference 2019, ACC Liverpool, 6-8 March 2019, diabetic medicine, Abstract: A18 (P376). Liverpool, 2019.

45 Schiøtz ML, Bøgelund M, Almdal T, et al. Social support and selfmanagement behaviour among patients with type 2 diabetes. Diabet Med 2012;29:654-61.

46 Hutter N, Scheidt-Nave C, Baumeister H. Health care utilisation and quality of life in individuals with diabetes and comorbid mental disorders. Gen Hosp Psychiatry 2009;31:33-5.

47 Kristensen MAT, Guassora AD, Arreskov AB, et al. 'I've put diabetes completely on the shelf till the mental stuff is in place'. How patients 
with doctor-assessed impaired self-care perceive disease, self-care, and support from general practitioners. A qualitative study. Scand $J$ Prim Health Care 2018;36:342-51.

48 Blixen CE, Kanuch S, Perzynski AT, et al. Barriers to self-

management of serious mental illness and diabetes. Am J Health Behav 2016;40:194-204.
49 Fisher L, Hessler D, Polonsky W, et al. Emotion regulation contributes to the development of diabetes distress among adults with type 1 diabetes. Patient Educ Couns 2018;101:(1873-5134 (Electronic)) 